\title{
2D Intermediate Suppression for Efficient Ruddlesden- Popper (RP) Phase Lead-Free Perovskite Solar Cells
}

Jian Qiu, ${ }^{\text {a } Y i n g d o n g ~ X i a, ~}{ }^{a}$ Yiting Zheng, ${ }^{a}$ Wei Hui, ${ }^{a}$ Hao Gu, ${ }^{a}$ Wenbo Yuan, ${ }^{a}$ Hui Yu, ${ }^{a}$ Lingfeng Chao, ${ }^{a}$ Tingting Niu, ${ }^{a}$ Yingguo Yang, ${ }^{b}$ Xingyu Gao, ${ }^{b}$ Yonghua Chen, ${ }^{a, c *}$ and Wei Huang ${ }^{\mathrm{a}, \mathrm{c}, \mathrm{d} *}$

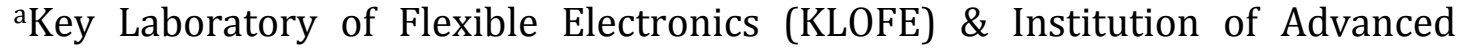
Materials (IAM), Jiangsu National Synergetic Innovation Center for Advanced Materials (SICAM), Nanjing Tech University (NanjingTech), 30 South Puzhu Road, Nanjing, Jiangsu, 211816, P. R. China

bShanghai Synchrotron Radiation Facility, Shanghai Institute of Applied Physics, Chinese Academy of Sciences, Shanghai 201204, P. R. China.

'Shaanxi Institute of Flexible Electronics (SIFE), Northwestern Polytechnical University (NPU), 127 West Youyi Road, Xi'an 710072, China

${ }^{\mathrm{d} K e y ~ L a b o r a t o r y ~ f o r ~ O r g a n i c ~ E l e c t r o n i c s ~ \& ~ I n f o r m a t i o n ~ D i s p l a y s ~(K L O E I D), ~ a n d ~}$ Institute of Advanced Materials (IAM), Nanjing University of Posts and Telecommunications, 9 Wenyuan Road, Nanjing 210023, China.

J. Qiu and Y. Xia contribute equally to this work.

Email: iamyhchen@njtech.edu.cn iamwhuang@njtech.edu.cn 


\section{Experiment Section}

Materials: PEDOT:PSS was purchased from Clevios. $\mathrm{C}_{60}$ and PCBM was purchased from Nano-C. Tin iodide $\left(\mathrm{SnI}_{2}\right.$, purity $\left.\geq 99.999 \%\right)$ and Tin oxide $\mathrm{SnO}_{2}$ solution (15\% in $\mathrm{H}_{2} \mathrm{O}$ colloidal dispersion) was purchased from Alfa-Aesar. Tin fluoride $\left(\mathrm{SnF}_{2}\right.$, purity $\left.>95 \%\right)$ and 2-Phenylethylamine hydrochloride (PEACl, purity $>98 \%$ ) were purchased from Sigma-Aldrich. Guanidinium iodide (GAI, purity $>99.99 \%$ ) and butylaminium iodine (BAI, purity $\geq 99.5 \%$ ) were purchased from Xi'an Polymer Light Technology Corp. N,N-dimethylformamide (DMF, anhydrous, 99.8\%), dimethyl sulfoxide (DMSO, anhydrous, 99.9\%), and chlorobenzene (CB, anhydrous, 99.8\%) were obtained from Sigma-Aldrich and formAmidinium iodide (FAI, purity $>99 \%$ ) was purchased from Shanghai MaterWin New Materials Co. Ltd.

Precursor Solutions: 3D Sn perovskite was obtained by mixing the FAI, $\mathrm{SnI}_{2}$, and $\mathrm{SnF}_{2}$ with a molar ratio of 1:1:0.6 in mixture of DMF and DMSO (v:v=4:1) in concentration of $250 \mathrm{mg} / \mathrm{mL}$. $\left(\mathrm{PEA}_{\mathrm{x}} \mathrm{BA}_{1-\mathrm{x}}\right)_{2} \mathrm{FA}_{3} \mathrm{Sn}_{4} \mathrm{I}_{13}$ were obtained by mixing PEACl, BAI, FAI, $\mathrm{SnI}_{2}$, and $\mathrm{SnF}_{2}$ with a molar ratio of $2 \mathrm{x}: 2(1-\mathrm{x}): 3: 4: 0.6(\mathrm{x}=0 \sim 1)$ respectively in mixture of DMF and DMSO (v:v=4:1) in concentration of 250 $\mathrm{mg} / \mathrm{mL}$ with $5 \mathrm{wt} \% \mathrm{GAI}$ as additive. All solutions were stirred for over $12 \mathrm{~h}$ at $60^{\circ} \mathrm{C}$ and were filtered before use.

Perovskite films deposition: The precursors and substrates were preheated at $60{ }^{\circ} \mathrm{C}$. Then the precursors were spin coated on substrate at $4000 \mathrm{rpm}$ for $40 \mathrm{~s}$ with chlorobenzene (CB) as anti-solvent. After that, the films were annealed at 100 ${ }^{\circ} \mathrm{C}$ for $5 \mathrm{~min}$. All operations were carried out in a nitrogen glove box.

Fabrication: ITO glass was cleaned and then treated by UV ozone for $15 \mathrm{~min}$ before use. PEDOT:PSS was spin coated at 5000 r.p.m. for $50 \mathrm{~s}$ and then annealed at $120^{\circ} \mathrm{C}$ for $30 \mathrm{~min}$. Then perovskite was spin coated on them. After that, $\mathrm{C}_{60}(30$ $\mathrm{nm}), \mathrm{LiF}(1 \mathrm{~nm})$, and $\mathrm{Al}(100 \mathrm{~nm})$ were evaporated under high vacuum. For device test, the device area was defined as $0.05 \mathrm{~cm}^{2}$.

Characterization: The device characteristics were measured under AM 1.5 G 
illumination using an Enlitech SS-F5-3A, and the $J-V$ characteristics were measured using the $J-V$ sweep software developed by Enlitech Ltd. and a Keithley 2400 source/meter unit. Current-voltage curves were measured in the forward scan range of -0.1 to $0.7 \mathrm{~V}$ and the reverse scan from 0.7 to $-0.1 \mathrm{~V}$. SEM and AFM images were obtained from JEOL, JSM-7800F and non-contact mode, Park XE7. XRD was obtained from Smartlab (3 kW). Time-resolved PL spectra (TRPL) were obtained from TCSPC (excited by $600 \mathrm{~nm}$ laser). XPS was obtained from ThermoFisher Escalab 250Xi using Al Ka X-ray with energy of $1486.6 \mathrm{eV}$. GIWAXS was obtained at beamline BL14B1 of the Shanghai Synchrotron Radiation Facility (SSRF).

Fabrication of electron-only and hole-only devices, and measurement and calculation of trap state density:

Preparation: The electron-only devices with structure of $\mathrm{ITO} / \mathrm{SnO}_{2}(\sim 40$ $\mathrm{nm}) /$ Perovskite $(130 \sim 160 \mathrm{~nm}) /$ PCBM $(\sim 80 \mathrm{~nm}) / \mathrm{LiF}(1 \mathrm{~nm}) / \mathrm{Al}(100 \mathrm{~nm})$ was fabricated by: 1 . spin coating (4000 r.p.m-30 s) $\mathrm{SnO}_{2}$ (dilution: $1 \mathrm{~mL} \mathrm{SnO} \mathrm{S}_{2}$ solution @ $5 \mathrm{~mL}$ water) and do annealing treatment ( $\left.150{ }^{\circ} \mathrm{C}-30 \mathrm{~min}\right)$. 2. spin coating 2DRP Sn perovskite. 3. spin coating (1000 r.p.m.-60s and then 2000 r.p.m.-2 s) PCBM (15-18 mg@1 mL CB).4. LiF and Al were evaporated under high vacuum.

The hole-only devices with structure of ITO/PEDOT:PSS $(\sim 40 \mathrm{~nm}) /$ Perovskite $(130 \sim 160 \mathrm{~nm}) / \mathrm{TFB}(80 \mathrm{~nm}) / \mathrm{MoO}_{3}(12 \mathrm{~nm}) / \mathrm{Au}(100 \mathrm{~nm})$ was fabricated by: 1. spin coating (5000 r.p.m.-50 s) PEDOT:PSS and do annealing treatment $\left(120{ }^{\circ} \mathrm{C}\right.$ $30 \mathrm{~min}$ ). 2. spin coating 2DRP Sn perovskite. 3. spin coating (2000 r.p.m.-40 s) TFB (8 mg@1 mL m-Xylene). 4. $\mathrm{MoO}_{3}$ and Au were evaporated under high vacuum.

Measurement: All devices are measured from 0-7 V with step size of 0.02 V under dark condition using the $J-V$ sweep software developed by Enlitech Ltd. and a Keithley 2400 source/meter unit.

Calculation: The electron- and hole-trap state density was calculated based on the equation:

$$
N_{\mathrm{t}}=\frac{2 \varepsilon_{0} \varepsilon_{r} V_{T F L}}{q L^{2}}
$$


Where $L$ is the thickness of perovskite film $(130-160 \mathrm{~nm}), \varepsilon_{r}(=25)$ is relative dielectric constant, $\varepsilon_{0}$ is the vacuum permittivity, $q$ is the elemental charge, and $V_{T F L}$ is the onset voltage of the trap filled limit region (Table S1) 
a)

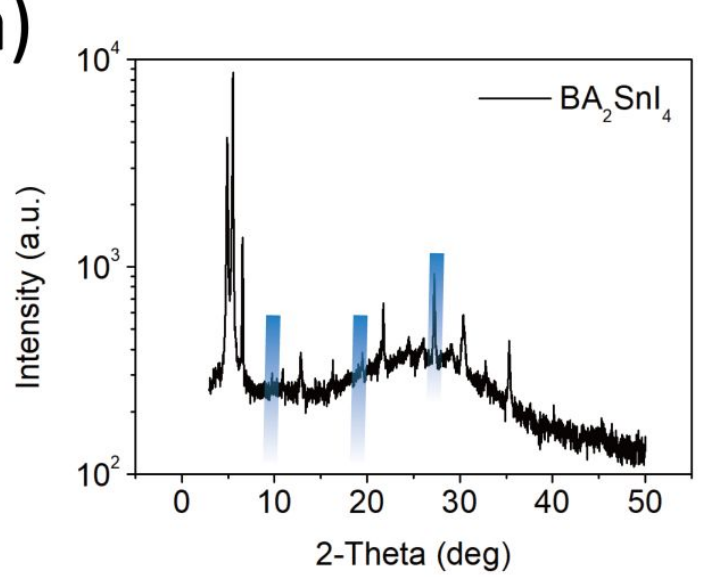

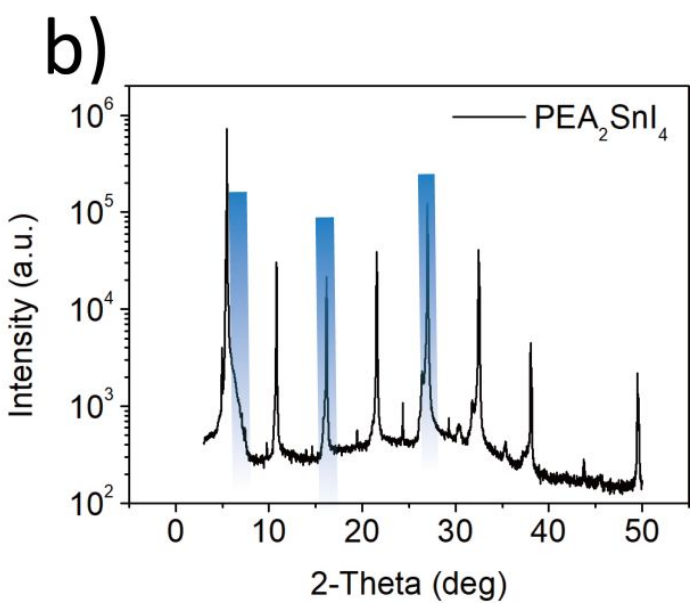

Figure S1. a) XRD pattern of 2D perovskite $\mathrm{BA}_{2} \mathrm{SnI}_{4}$. b) XRD patterns of 2D perovskite $\mathrm{PEA}_{2} \mathrm{SnI}_{4}$. 
a)

b)
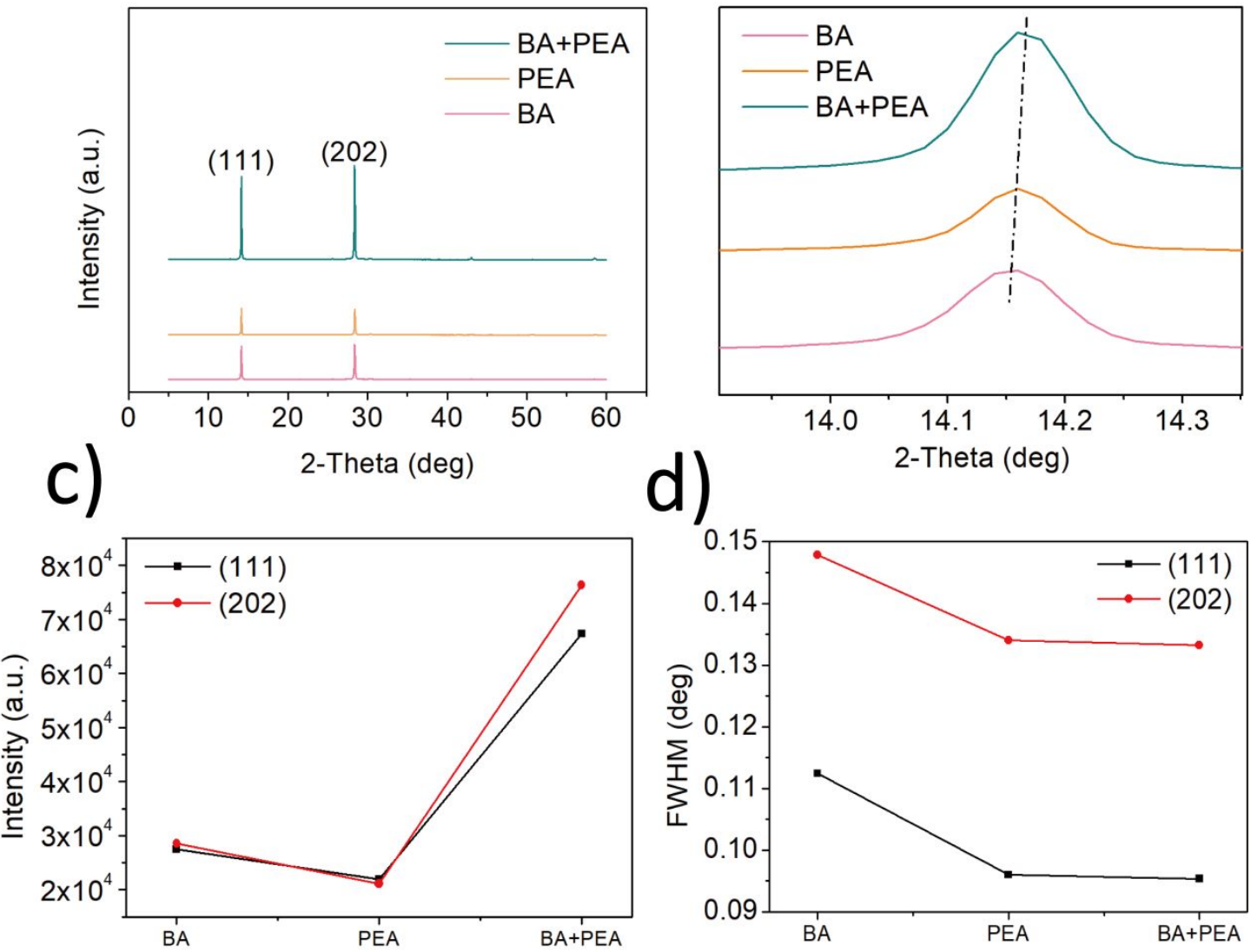

Figure S2. a) XRD patterns and b) magnified view of fabricated 2DRP Sn perovskite films based on BA, PEA, BA+PEA. c) Intensity of (111) and (202) based on different systems. d) FWHM of (111) and (202) based on different systems. 


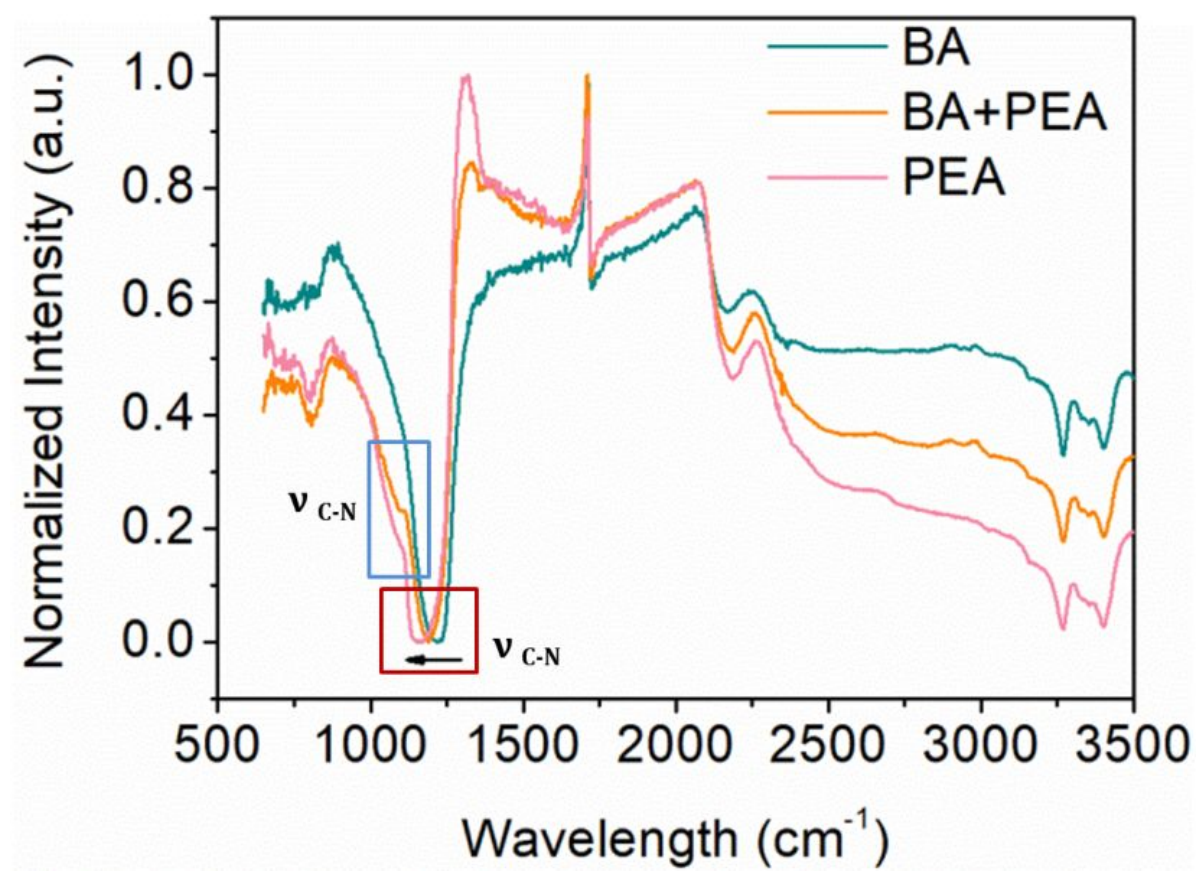

Figure S3. Fourier transform infrared spectroscopy (FTIR) based on BA, PEA, and BA+PEA 2DRP Sn perovskite films. 


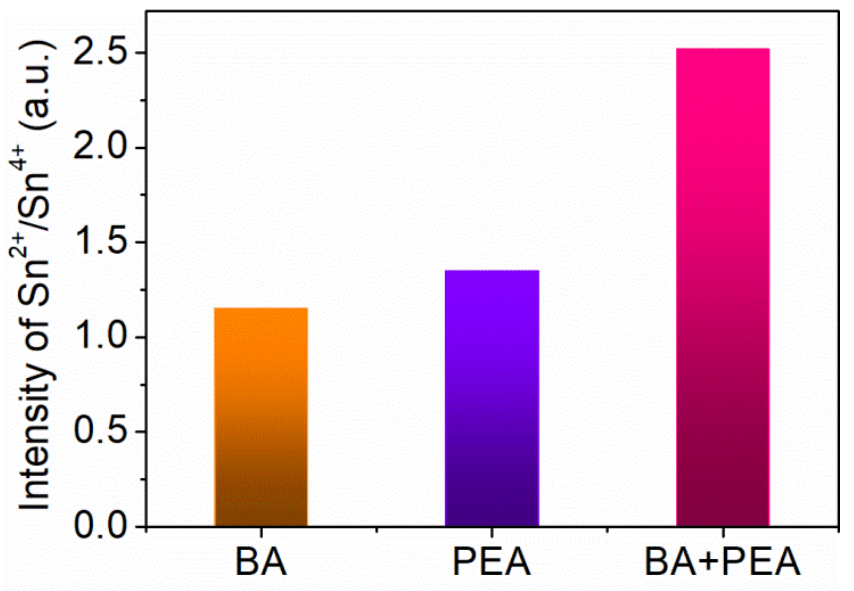

Figure S4. Intensity of $\mathrm{Sn}^{2+} / \mathrm{Sn}^{4+}$ of $2 \mathrm{DRP}$ Sn perovskite films based on BA, PEA, and BA+PEA. 

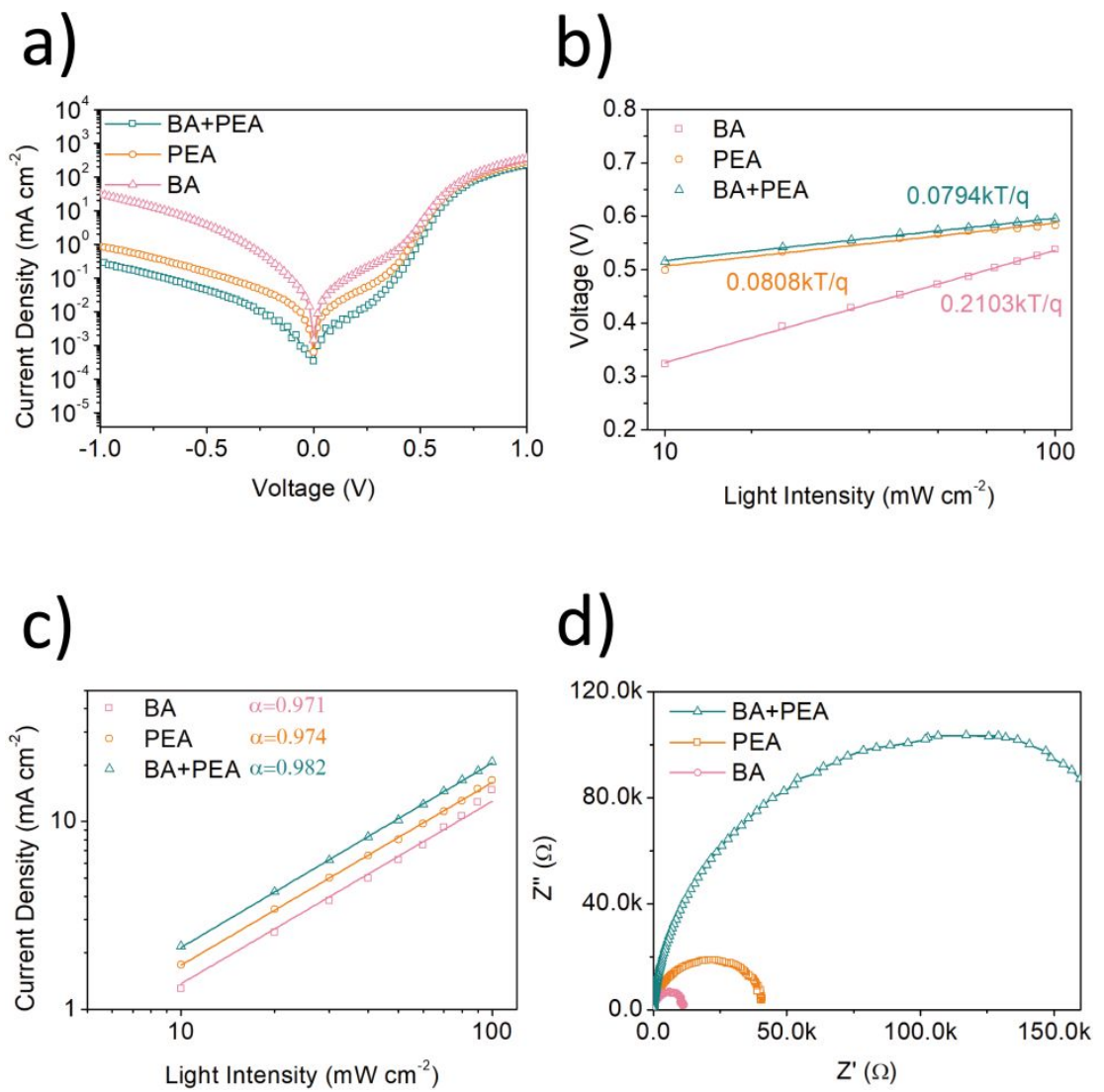

Figure S5. a) Dark currents of 2DRP Sn perovskite devices based on BA, PEA, and BA+PEA. b) $\mathrm{V}_{\mathrm{oc}} V S$ light, c) J $\mathrm{sc}_{\mathrm{sc}} V S$ light, and d) Impedance spectra of 2DRP Sn perovskite devices based on $\mathrm{BA}, \mathrm{PEA}$, and BA+PEA. 

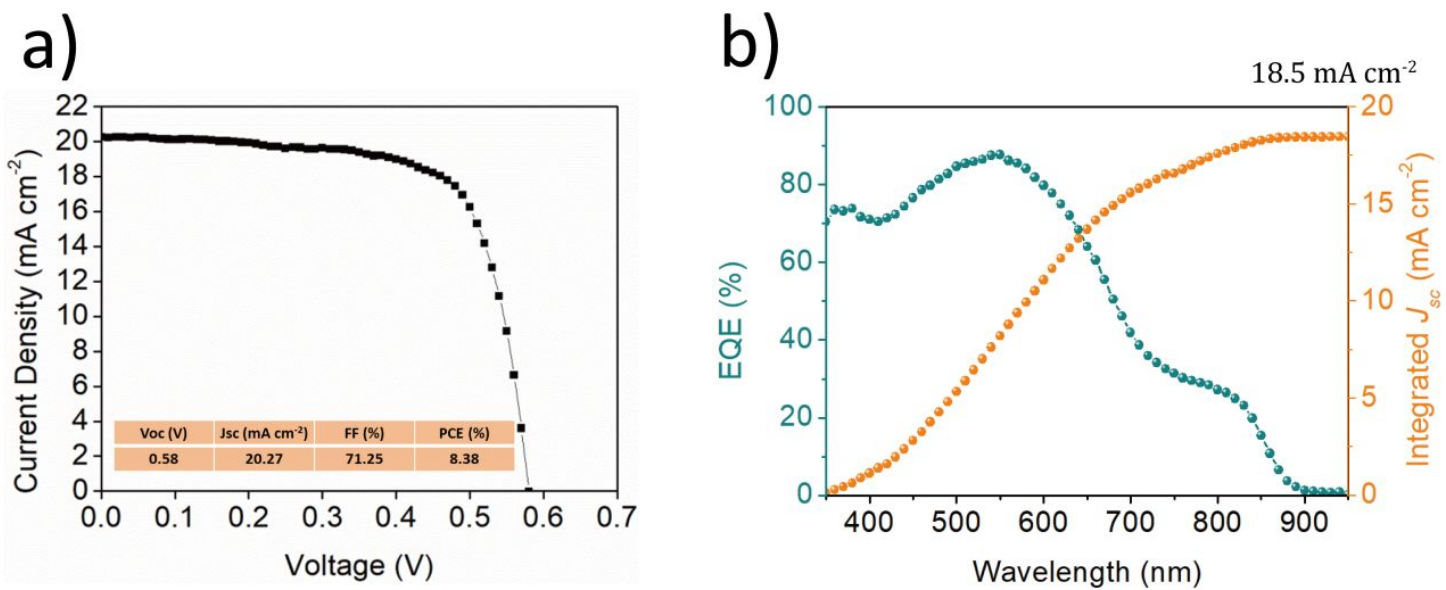

Figure S6. a) Performance of device used to test external quantum efficiency (EQE). b) EQE test of 2DRP Sn perovskite device. The difference between short circuit current and integrated current is $1.77 \mathrm{~mA} \mathrm{~cm}^{-2}$. 

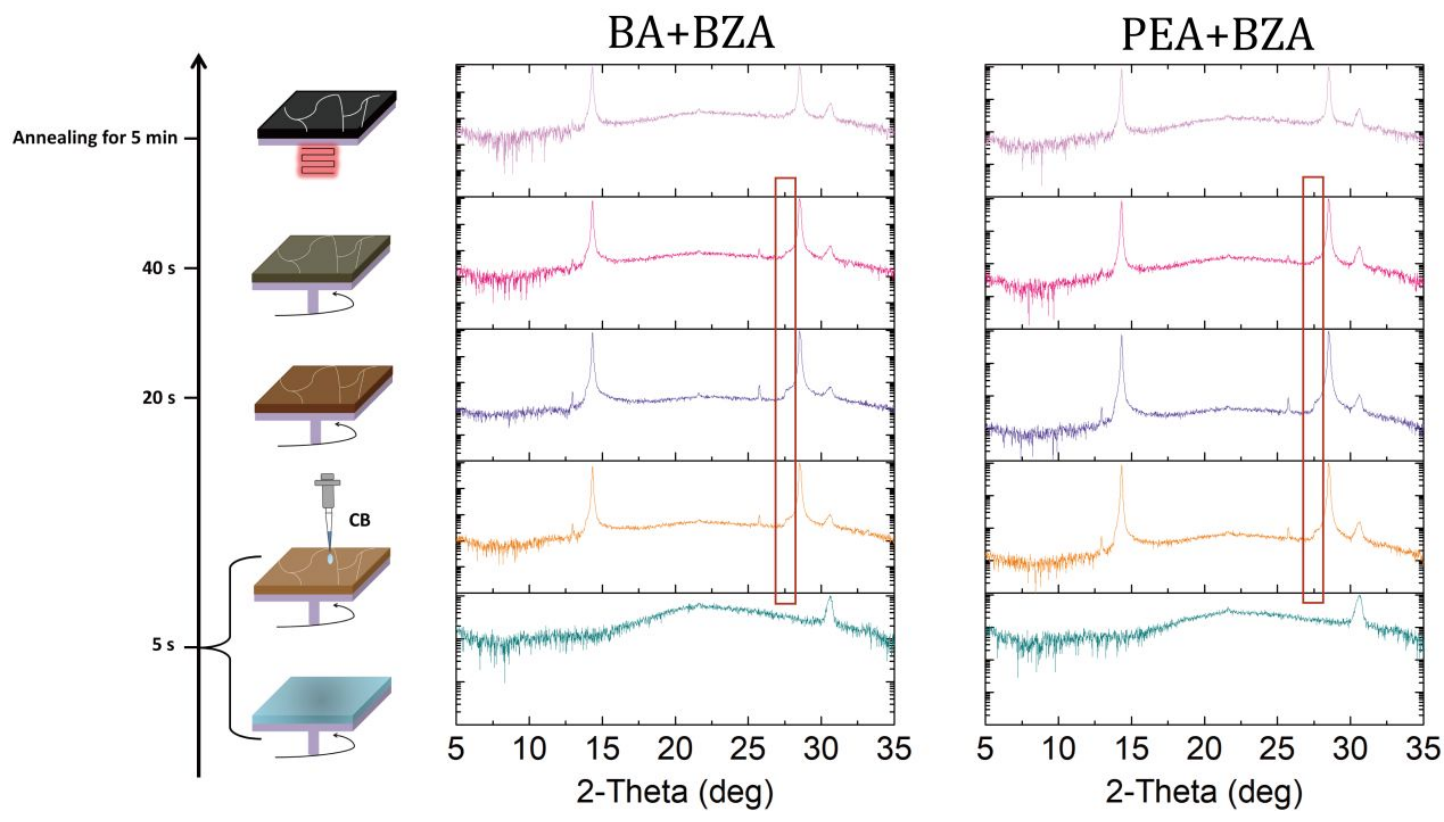

Figure S7. The evolutions of XRD patterns of 2DRP Sn perovskite (BA+BZA and PEA+BZA) depending on the film fabrication process. 
Table S1. The onset voltage of the trap filled limit region based on BA, PEA, and BA+PEA.

\begin{tabular}{ccc}
\hline Spacers & $\mathrm{V}_{\mathrm{TFL}}$-electron $(\mathrm{V})$ & $\mathrm{V}_{\mathrm{TFL}}$-hole $(\mathrm{V})$ \\
\hline BA & 0.50 & 1.12 \\
PEA & 0.36 & 0.32 \\
BA+PEA & 0.10 & 0.18 \\
\hline
\end{tabular}


Table S2. Summary of device performance based on different introduction of PEA ${ }^{+}$.

\begin{tabular}{ccccc}
\hline $\begin{array}{c}\text { BA-PEA [x-(1- } \\
\mathrm{x})]\end{array}$ & $\mathrm{V}_{\mathrm{oc}}(\mathrm{V})$ & $\mathrm{J}_{\mathrm{sc}}\left(\mathrm{mA} \mathrm{cm}^{-2}\right)$ & $\mathrm{FF}(\%)$ & PCE (\%) \\
\hline 1 & 0.55 & 16.92 & 59.57 & 5.55 \\
0.7 & 0.48 & 17.58 & 50.60 & 4.28 \\
0.5 & 0.60 & 21.82 & 66.73 & 8.82 \\
0.3 & 0.56 & 18.30 & 49.32 & 5.07 \\
0 & 0.58 & 16.57 & 66.56 & 6.42 \\
\hline
\end{tabular}


Table S3. A summary of high-efficiency Sn based PSCs in current (including Perovskite, PCE, References and Type).

\begin{tabular}{|c|c|c|c|}
\hline Perovskites & PCE & References & Type \\
\hline $\mathrm{FA}_{0.75} \mathrm{MA}_{0.25} \mathrm{SnI}_{3}$ & $9.06 \%$ & ACS Energy Lett. 2018, 3, 2701 & 3D \\
\hline $\mathrm{BA}_{0.15} \mathrm{FA}_{0.85} \mathrm{SnI}_{3}-1 \% \mathrm{EDAI}$ & $8.90 \%$ & Energy Environ. Sci. 2018, 11, 2353 & Mixed dimensional \\
\hline $\mathrm{PEA}_{0.15} \mathrm{FA}_{0.85} \mathrm{SnI}_{3}-\mathrm{NH}_{4} \mathrm{SCN}$ & $9.40 \%$ & Joule 2018, 2, 1 & \\
\hline $0.08 \mathrm{PEA}_{2} \mathrm{SnI}_{4}+0.98 \mathrm{FASnI}_{3}$ & $9.00 \%$ & Adv. Energy Mater. 2017, 1702019 & \\
\hline $\mathrm{GA}_{0.2} \mathrm{FA}_{0.78} \mathrm{SnI}_{3}-1 \%$ EDAI & $9.60 \%$ & Adv. Mater. 2018, 180483 & \\
\hline $\mathrm{AVA}_{2} \mathrm{FA}_{4} \mathrm{Sn}_{5} \mathrm{I}_{16}$ & $8.71 \%$ & Adv. Funct. Mater. 2018, 1807696 & \\
\hline $\mathrm{PEA}_{2} \mathrm{FA}_{8} \mathrm{Sn}_{9} \mathrm{I}_{28}$ & $5.94 \%$ & J. Am. Chem. Soc. 2017, 139, 6693 & 2DRP \\
\hline $\mathrm{BA}_{2} \mathrm{MA}_{3} \mathrm{Sn}_{4} \mathrm{I}_{13}$ & $2.50 \%$ & ACS Energy Lett. 2017, 2, 982 & \\
\hline $\mathrm{BA}_{2} \mathrm{MA}_{3} \mathrm{Sn}_{4} \mathrm{I}_{13}$ & $4.03 \%$ & Adv. Sci. 2018, 1800793 & \\
\hline$(4 \mathrm{AMP}) \mathrm{FA}_{3} \mathrm{Sn}_{4} \mathrm{I}_{13}$ & $4.22 \%$ & $\begin{array}{c}\text { ACS Energy Lett. 2018, DOI: } \\
\text { 10.1021/acsenergylett.8b02051. }\end{array}$ & 2DDJ \\
\hline$\left(\mathrm{BA}_{0.5} \mathrm{PEA}_{0.5}\right)_{2} \mathrm{FA}_{3} \mathrm{Sn}_{4} \mathrm{I}_{13}$ & $8.82 \%$ & This work & 2DRP \\
\hline
\end{tabular}

